\title{
NOTAS
}

\section{Las novelas clásicas mexicanas de los últimos veinticinco años}

En los últimos veinticinco años, la novela mexicana ha tenido un desarrollo muy notable. Será quizá porque existe ya una mayor conciercia de los problemas políticos, económicos y sociales del país y es la narrativa el género más adecuado para reflejar el espíritu que la produce.

En cuanto a nuestra tradición novelística, cabe reconocer que ésta no ha sido ni muy larga ni muy brillante. Es verdad que históricamente se produce en México en el siglo xix la primera novela hispanoamericana, pero también es cierto que no se publicó entre nosotros la obra más leída, ni la más imitada, ni la más comentada, ni la mejor escrita. Tampoco tuvimos la suerte de que en nuestro país alentara el personaje de mayor vitalidad ni la trama más alucinante. Aquí el género nació un tanto deformado por ingredientes extraliterarios: la prédica moralizante absorbía todas las posibilidades de la imaginación, del mismo modo que el desahogo político enturbiaba la mesura y el equilibrio de la razón.

En la historia política y social, nuestro siglo xx se abre con la Revolución de 1910, y en la literaria, las experiencias que ilustran una etapa tan confusa y cruel forman, años después, el grupo conocido de los No. velistas de la Revolución.

Es posible explicar la indiferencia con que se recibió la novela Los de abajo de Mariano Azuela, la primera de este ciclo en 1916. ¿A quién le interesaba la historia de un guerrillero de nombre supuesto, si cada uno tenía la suya propia o había participado en las peripecias dramáticas de algún amigo, pariente o vecino? ¿Para qué renovar la herida, 
si en cada familia dispersa sus hombres habían quedado colgados en los postes del telégrafo; acribillados en las plazas o en los cementerios de los pueblos, en el campo raso o en cualquier encrucijada? Los muertos especialmente, pesaban en las noches calladas; se revolvían ante el recuerdo más leve, y clamaban venganza en los oídos tensos de hijos abandonados y de mujeres ultrajadas.

Sin embargo, el primer testimonio escrito estaba ahí, y unos años más tarde - seis o siete- el tema y el ejemplo de Azuela es reiterado con diferentes matices, con diversos enfoques, para formar un importante grupo de novelas que presentan un testimonio humano, pero con un criterio estrictamente interesado, de alcance épico porque es la expresión de anhelos populares.

Aunque limitadas en más de un aspecto, estas narraciones transformaron los antiguos moldes de la novelística mexicana, liquidando así la tradicional separación que había entre la vida y la literatura, y haciendo que ésta entrara, como los soldados de la Revolución a los palacios potfiristas. Palpitantes de vida, de muerte, de violencia, de sangre, de hambre y de venganza, estas páginas no son solamente crónicas de un hecho histórico. Mal haríamos en desdeñar el trabajo de este grupo de escritores, si aceptásemos para ellos el título de cronistas que algunos críticos tratan de aplicarles. Pues si bien es cierto que fueron partícipes en los hechos que narran, no por ello debe ignorarse que esos datos y hechos, por razón de haber sido interpretados y organizados literariamente, son una recreación de la vida $y$, por lo tanto, un producto legítimo del arte narrativo. El material, sin duda, es la realidad con su enorme presencia, pero es el autor quien se enfrenta a ella y sobre ella decide. Lo que conocemos es el punto de vista del artista; lo que apreciamos es su sagacidad, su sentido dramático, su fuerza, su concepción de ese mundo violento y hosco. El personaje onmipresente no tiene rostro ni nombre; es un pueblo que se desangra y lucha por sus derechos elementales. Los líderes o cabecillas dibujan apenas la huella de su presencia en un grito, en una frase o en una actitud. Su influencia nefasta o luminosa determina una variante, pero nada es duradero, ni estable, ni firme. Y... aquí vendría una imagen imborrable que la novela nos entrega: la del México revolucionario, la de un momento de furor destructivo. Grupos desordenados de hombres, en su mayor parte campesinos, invaden los caminos del país, dispuestos a pelear contra un enemigo común no bien identificado. El cabecilla, determinado por el azar, puede ser cualquiera. Sobre la marcha y bajo el peso de una responsabilidad que en todo momento ejerce su tiranía, va tomando conciencia del papel que le toca 
representar, seguro de que su camino está marcado, y seguro también de que será arrastrado junto con los otros por una fuerza que no puede detenerse. Y muy pronto aparece la desilusión, el pesimismo por un sacrificio inútil, por unos resultados negativos, porque en la tarea de reconstruir se tropieza con la ambición personal y el delirio de poder.

El hecho de que nuestros novelistas más singulares del momento tengan tantos puntos de contacto con los más celebrados de otros países latinoamericanos, es tan obvio, que ya resulta difícil hablar de Cortázar sin mencionar a Fuentes; referirse a Garcia Márquez sin aludir a sus años de vida en México, y no advertir que Vargas Llosa, Rulfo, Cortázar, Fuentes, no son escritores improvisados y que han caminado muchos siglos de literatura, aunque muchos de ellos sean muy jóvenes, y que viven en un mismo mundo cuyos límites se han abierto hasta desaparecer. Los recursos que manejan narradores como Asturias, Carpentier, Borges, Yáñez y los otros, son riquísimos, con un fuerte acento sobrerrealista, ya que esa línea of rece, como ninguna otra, mayor libertad. La protesta está implícita, pero no es panfletaria sino vital. El lugar que generalmente eligen para sus obras puede ser inexistente, pero siempre reúne acusados caracteres que lo hacen genérico de un país. Si los personajes se desplazan, a cualquier lugar del mundo les acompaña un lastre de recuerdos del que no logran desprenderse. Curiosamente se internacionalizan en busca de su identidad. Se destrozan entre sus alardes por destruir sus mitos y por sacudirse la ataduras de una tradición estrecha: intelectual, moral, religiosa y social. En este proceso los encontramos: en la tremenda tarea de vivir su momento con todo lo que ello implica; vivir, no por ni para; simplemente vivir, si simplemente significa vivir con conciencia.

En el año de 1943 aparece en México la novela El luto bumano, de José Revueltas, y en 1947 Al filo del agua, de Agustín Yáñez. En ambas, los procedimientos del realismo objetivo, reducido y repetido con insistencia por las novelas de la Revolución inscritas en segunda y tercera fila, se abandonan casi totalmente para incorporar otros con los que se atiende a reflejar, tanto la desilusión y pesimismo que ese movimiento trajo consigo, como la angustia originada por la crisis mundial inmediatamente anterior a la segunda gran guerra.

El luto bumano se orienta hacia dimensiones subjetivas; bucea en el interior de un ser desesperanzado, miserable y humillado, movido por sus instintos. Este hombre, que generalmente representa lo más miserable social y espiritualmente, no tiene redención ni escape. La atmósfera que lo oprime es tan indiferente y precisa en la destrucción, tan conta- 
minada de sordidez y dolor, que las relaciones con el mundo exterior se tornan nebulosas, irreales en el ritmo y en el lenguaje.

En su lucha contra un mundo de desorden y sombras, utiliza la violencia, la aspereza, la impiedad obscena. Una fuerza sombría y alucinada arrebata en ocasiones la narración con un cálido temblor poético. En otras, la alegoría simplista, la retórica ampulosa, las obsesiones y pasiones anulan el poder de su vigoroso acento. Con sus imperfecciones - excesos, la obra de Revueltas señaló a la narrativa mexicana nuevos caminos aprendidos, quizá más de cerca que en Proust y Joyce, en los maestros norteamericanos. Llamó la atención hacia regiones inexploradas y oscuras del espíritu humano; interpretó la inseguridad en que agoniza el hombre moderno hundido en la soledad, el miedo y el asco. Aplica recursos literarios que si bien no se utilizaban por primera vez en México, sí eran, en su caso, coherentes con la intención intima del relato: el monólogo interior, la conciencia libre de un "testigo" que determina el ordenamiento de la narración, el trastorno cronológico, las diversas proyecciones de un mismo hecho en las conciencias de diferentes personajes, la atmósfera irreal y agobiante de la pesadilla. Identificados sus personajes y los hechos que narra muy de cerca con sus propias experiencias, hay en ese mundo confusión, debilidad, lágrimas, errores y luto, junto con un anhelo de orden, de redención y de verdad.

Si bien es cierto que el intento de Revueltas no cayó en el vacío, y su afán innovador fue saludado con interés, la aparición de $A l$ filo del agua, de Agustín Yáñez, afianza con brillantez y seguridad las nuevas conquistas.

Por el hecho de ubicar su obra lejos de la gran ciudad, relacionándola de manera tan estrecha con el asunto de la Revolución, tal parecía que Yáñez retomaba un aspecto que se suponía agotado. Pronto se vio que su interés era otro. En vez de relatar hechos, presentaba una situación y se aventuraba por los vericuetos de la conciencia de un pueblo torturado por las llamadas pasiones del alma: mundo, demonio y carne. El momento anterior al estallido de la Revolución, cuando los sistemas de represión llegan a su punto máximo, sirve de marco a la obra.

El ambiente general se da en el Acto preparatorio: Pueblo de mujeres enlutadas, pueblo sin alegría. Falso sentimiento religioso, temores justificados e injustificados, hipocresía y pesimismo. Aire conventual de cautela y hermetismo. Pueblo cerrado a las ventajas del progreso, vuelto hacia la tradición petrificada; intolerante con las debilidades de la carne; gobernado por una justicia omnipresente pero sensible sólo para el pecado. 
Con furtivos intentos de acercamiento asoma el testigo a las calles desiertas y sin embargo cuidadosamente limpias. Atisba en los patios y cuartos despejados de adornos pero invadidos en rincones, detrás de las puertas y bajo las camas. Sorprende las actitudes disimuladas de las mujeres que apenas se saludan cuando tropiezan camino de la iglesia. Precipitan las palabras pero retienen el paso. La oración mecánica mueve sus labios, pero la mirada divaga y se pierde ahí mismo. Sin duda en lo oue esconden, en lo que ocultan, en lo que disimulan, en lo que guardan estos seres aparentemente secos, está el verdadero sentido de sus vidas. Se establece entonces un plan para sorprenderlos. Para descubrirlos será menester develar sus insomnios, penetrar en sus sueños, alcanzar sus delirios. Sólo ahí empezarán a dibujarse sus mezquindades secretas, sus descos inconfesables, sus miedos monstruosos. En este momento se descubre el engaño. La austeridad hipócrita mal encubre el acoso del instinto que cobra un poder demoníaco, insaciable. El conflicto no puede terminar sino en frustración, locura o muerte.

El novelista ha cambiado su actitud. Utiliza los caminos que lo llevan directamente a la conciencia del hombre. Su cosmovisión le permite ordenar los fragmentos de las experiencias aisladas en una unidad armónica que vale por sus elementos y por el conjunto. La simultaneidad, manejada en extensión, se refuerza con las calas en profundidad. El juego de apariencias en contrapunto agobiante, va descubriendo morosamente el verdadero drama interno de un pueblo. Es decir, de las infinitas técnicas de la novela contemporánea, Yáñez ha elegido las que convienen para el estudio de este conflicto, conocido de manera tan completa hasta sus consecuencias últimas. Es indudable que ha elegido bien y que sus medios expresivos responden a una necesidad real, interna de la obra. Yáñez nos ha hecho una revelación inquietante, mostrando el revés de la trama. El fluir de la conciencia rompe la continuidad objetiva pero permite, a cambio, dar la turbadora imagen de la lucha interior en que la obsesión pecaminosa, el arrebato lírico, la ensoñación, el odio, el descubrimiento amoroso, se asoman al litoral de la conciencia y tratan de romper los diques de silencio y obediencia que les impiden manifestarse.

Sin duda alguna, en la obra novelística total de Yáñez, valiosa por sus experiencias formales y por la intención de abarcar en varios ciclos el desarrollo general del país, habría que detenerse para señalar su agudo sentido crítico y sus importantes logros estilísticos; su aliento épico y los variados matices con que enriquece la pincelada recargada e insistente de su primera gran novela; su lenguaje cambiante y pródigo como 
la tierra, o enjuto y profundo, sentencioso, grave como la región donde brota. Quizá tendríamos que detenernos en sus personajes memorables en sus dimensiones trágicas, pero nos bastará por ahora poner de manifiesto la importante contribución que Yáñez ha dado a la novela de los autores más jóvenes.

En el año de 1953 aparece el volumen de cuentos de Juan Rulfo, El llano en llamas y dos años más tarde su novela Pedro Páramo. Su aparición fue considerada como un acontecimiento en la literatura mexicana, y a la vez provocó que una secuela de imitadores trataran de acercarse al medio rural con los procedimientos con que Rulfo recreara el trasfondo de destrucción y rencor que la Revolución sembró en los campos. Rulfo eligió un mundo agrario, limitado y paralítico, habitado por resentimientos, golpeado por elementos de la naturaleza, sumido en una vida excesivamente precaria, pero presente en toda su obra como parte de su propia experiencia vital. Para comunicar la impresión que de ella tiene, toma sitio dentro de la conciencia de sus personajes, y desde esa estrecha ventana registra, sin proyección ni orden, las impresiones que le llegan del pasado espontáneamente, por asociaciones libres, en un ir y venir lento y monótono. Nunca antes de estos escritores había sido tan aguda la preocupación por el conocimiento del hombre. Las tentativas de llegar al fondo del misterio, el deseo de autenticidad, proponen enfoques sorprendentes que si bien desconciertan, no están o no deben estar en función de un juego vano, sino efectivamente sopottando una necesidad interna, iluminando la diversificación de un mundo en efecto dislocado y ciertamente fantástico por incongruente.

Rulfo da, en ocasiones, la impresión de que ha llevado demasiado lejos sus experiencias. Utilizando métodos del sobrerrealismo, trueca en seres animados a las cosas, y a los elementos de la naturaleza en personajes con voluntad y decisiones. Los hombres, en cambio, reducidos a sombras untadas sobre el paisaje fantasmal, sólo disponen de movimientos descoyuntados y mecánicos y de la inercia de la espera. La muerte y. la vida han borrado sus fronteras; la niebla del recuerdo difumina los contornos y adelgaza las voces en murmullos y rumores. Con estas trasposiciones y a una lívida luz que proviene lo mismo de un sueño que de una evocación, se proyecta el calosfrío de la turbadora, por inevitable, sensación de caída del hombre en la enajenación del ambiente de desolación y desesperanza. En la creación de esta visión del mundo, válido para un grupo de seres humanos, se han utilizado diversos planos temporales y diferentes enfoques, pero sobre todo se hace uso de un lenguaje estilizado, subordinado al relato, intenso, trabajado, sobrio, su- 
gerente. La reiteración, el monólogo interior, la eliminación de lo trivial en las formas coloquiales, el acento en los giros inconfundibles del lenguaje, hacen de este autor uno de los que con mayores éxitos ha llevado a cabo la renovación en el terreno narrativo.

Aprovechando las realizaciones de la literatura norteamericana, Rulfo escribe su colección de cuentos y su única novela hasta ahora, Pedro Páramo. Sin una gran diferencia en los esquemas y en la realización, Rulfo une, en ambas obras, a la sobria perfección estilística, su tendencia a fundir lo regional en lo universal y a dar una visión desolada y trágica del hombre moderno.

Es probablemente la ciudad, la gran ciudad, la que de manera más completa ha propiciado las transformaciones que el hombre ha sufrido en los últimos años. En el caso de México el fenómeno de gran concentración humana, agravado dia a día, ha traído al lado de problemas económicos y sociales, el personal y privado de la intolerancia, del anonimato y, en consecuencia, el de la soledad. La situación que ha planteado el crecimiento urbano a los profesionales en diferentes campos de la cultura atrae también a los novelistas, quienes no ajenos a la importancia del hecho, se acercan al hombre dentro de la sociedad, dentro de la colmena humana. Las repetidas experiencias de un acercamiento semejante proporcionan un saldo poco halagüeño: "soledad enfermiza, quiebra de las tradiciones, ineficacia del sentimiento amoroso y de la religión; el impacto de la mecanización de la vida moderna y los conflictos entre el artista y la sociedad". Con todo, ni los pensadores jóvenes ni los artistas están dispuestos a ahogarse entre multitudes sin rostro y ruido de motores. Debido a la presión de la colectividad sobre la individualidad, han hecho el más serio intento de descubrir su ser más verdadero y de liberarse de todos los engaños. El famoso libro de Octavio Paz, El laberinto de la soledad, puso en crisis los falsos valores atribuidos al mexicano. Sus valientes afirmaciones, su agudo análisis, su impertinente insistencia al tocar los tabúes y desnudar las palabras, provocaron reacciones muy violentas aunque en el fondo saludables. Paz representa desde hace años al hombre de letras más admirado dentro y fuera de México. Los jóvenes repiten sus juicios y sus versos con reconocimiento; una generación de filósofos se dedicó a profundizar los temas que él propuso. Los novelistas, inspirados en algunos conflictos de origen, que Paz atribuye al mexicano, le entregan como trofeos: máscaras, banderas nacionales, figuritas prehispánicas y "cortinas de nopal". Fuera del país se estudia su obra poética, se le cita como fuente crítica autorizada y como al mexicano que mejor conoce el carácter y las debilidades de los otros mexicanos. 
Nuestro novelista joven más comentado y discutido hoy en dia, Carlos Fuentes, tiene con Paz estrecha cercanía. Además de la amistad que los une, se asemejan en muchos puntos: profesionalismo, cultura, brillantez, cosmopolitismo, y un violento desprecio por lo mediocre, caduco o cursi. Aunque la obra narrativa de Fuentes, desde 1954 hasta la fecha, es rica y desigual, nos detendremos un momento en su primera novela, La región más transpparente, del año 1959, porque es la más reveladora de su intención como escritor y de los medios que utiliza. Parte del plan ambicioso de retener en un mural gigantesco los grupos sociales que componen la ciudad, y crea realmente la ilusión de la multiplicidad con vívidas descripciones de escenas representativas, a base de un lenguaje que sin rebozo en la intención, subraya con sus deformaciones y mecanismos el estrato social que le da sus peculiaridades. La actitud de Fuentes ante su material es de impaciencia. Si han de tomarse en serio sus declaraciones, parece estar convencido de que en un México millonatio y mísero, extravagante y trivial, donde no hay tragedia, todo se vuelve afrenta; y de que sólo a contrapelo, mortificando, hiriendo, aparece la verdad.

Esta biografía de la ciudad, es una amarga historia de debilidades y corrupción. Falsos brillos, falsos valores, falso orgullo, falsa tradición, ambiguo origen, caminos inciertos. La mirada penetrante del testigo omnipresente desnuda los mitos y descubre las trampas. Y ésta parece ser la mayor preocupación de Fuentes: destruir los fetiches, romper los vejestorios inútiles. En sus manos hábiles la palabra es una arma y un torrente. Hiere, ultraja, arrastra y limpia. Como es consecuente consigo misno, no disimula el origen de sus recursos expresivos; todos pueden ser suyos en el momento en que los necesita: los literarios, los pictóricos, los cinematográficos. Viaja con soltura por la soterrada historia antigua y por el caótico pasado inmediato, sin estaciones ni esperas. Utiliza un vocabulario amplio, artificioso, arcaico, soez, siempre abundante y matizado.

Más audaz que ninguno de nuestros escritores de hoy, capacitado como pocos para conocer un México que alternativamente ama y detesta, ha puesto en evidencia, mejor que otros escritores las grandes posibilidades de la novela mexicana o de los novelistas mexicanos, así como sus peligros. Se ha criticado en Fuentes su extremado pesimismo, su excesiva retórica, sus alardes en el manejo de técnicas narrativas; la insistente presencia del sexo como elemento determinante y lo confuso y abigarrado del conjunto. Con todo, La región más transparente es muy valiosa como experiencia, muy reveladora como intención, tanto, que aún reco- 
nocidas sus fallas ha oscurecido las obras más maduras de Fuentes: La muerte de Artemio Cruz y Cambio de piel.

Sin la aparición de Fuentes y de nuestros novelistas mayores de estos últimos veinte años, no podría explicarse la obra de los escritores más jóvenes: su libertad expresiva, el derecho a exhibir sus experiencias y su desencanto; la agresiva impaciencia por desconocer tradiciones, fronteras y códigos y, en consecuencia su afán por encontrar caminos insospechados heterodoxos o tradicionales para hacer patente la vibrante rebeldía, signo de nuestro tiempo.

María del Carmen Millán

Centro de Estudios Literarios

Ciudad Universitaria, México, D. F. 
